\title{
Caracteres morfológicos e rendimento de grãos de híbridos simples de milho em diferentes ambientes
}

\author{
Morphological characteristics and grain yield of simple corn hybrids in different environments
}
Tiago Olivoto', Ivan Ricardo Carvalho ${ }^{2 \star}$, Maicon Nardino², Mauricio Ferrari ${ }^{2}$, Alan Junior de Pelegrin ${ }^{2}$, Vinícius Jardel Szareski ${ }^{2}$, Gustavo Henrique Demari² \& Velci Queiróz de Souza ${ }^{3}$

${ }^{1}$ Universidade Federal de Santa Maria, Santa Maria, RS, Brasil.

${ }^{2}$ Universidade Federal de Pelotas, Capão do Leão, RS, Brasil. * Autor para correspondência: carvalho.irc@gmail.com.

${ }^{3}$ Universidade Federal do Pampa, São Gabriel, RS, Brasil.

Submissão: 17/09/2015 | Aceite: 13/06/2018

\begin{abstract}
RESUMO
O objetivo deste trabalho foi avaliar o comportamento dos caracteres morfológicos e o rendimento de grãos de híbridos simples de milho cultivados em diferentes ambientes. Foram conduzidos três ensaios no Rio Grande do Sul, utilizando o delineamento experimental de blocos casualizados em esquema fatorial, sendo sete (híbridos simples) $x$ três (ambientes de cultivo), dispostos em três repetições. Na análise de variância conjunta observou-se interação genótipos $x$ ambientes para os caracteres diâmetro da espiga, número de grãos por fileira, diâmetro do sabugo, massa de grãos por espiga e rendimento de grãos. $O$ número de fileiras por espiga e a massa de mil grãos não sofreram influência dos ambientes de cultivo sendo características intrínsecas de cada genótipo. O comprimento da espiga foi similar entre os híbridos, sendo influenciado apenas pelo ambiente de cultivo. A altura de planta e prolificidade foram maiores em Vista Gaúcha, RS, já em Tenente Portela foi observado maior altura de inserção de espiga, número de grãos por fileira, massa de espiga, massa de grãos por espiga e rendimento de grãos. Os híbridos DKB 290 PRO $3^{\circledR}$ e DKB 315 PRO $3^{\circledR}$ apresentaram as maiores produtividades na média dos ambientes estudados.
\end{abstract}

PALAVRAS-CHAVE: Zea mays L., caracteres morfo-agronômicos, potencial produtivo, resposta morfológica.

\begin{abstract}
The aim of this study was to assess the behavior of morphological components and yield of simple hybrid corn grains cultivated in different environments. Three field trials were conducted in the state of Rio Grande do Sul under an experimental randomized block design with factorial treatment: seven (simple hybrids) $x$ three (cultivation environments) arranged in three replications. The analysis of variance showed significant interaction between genotype and environment for the traits ear diameter, number of kernels per row, cob diameter, grain mass per ear and grain yield. The number of grains per rows and thousand-grain weights were not influenced by environments, being intrinsic characteristics of each genotype. The length of the cob presents similar among the hybrids, being influenced only by the cultivation environment. The plant height and prolificacy were higher in Vista Gaúcha, RS, however, Tenente Portela, RS, had a higher ear insertion height, grain number per row, ear mass, grain mass per ear and grain yield. Hybrids DKB 290 PRO $3^{\circledR}$ and DKB 315 PRO $3^{\circledR}$ presented the highest yields in the average of the environments studied.
\end{abstract}

KEYWORDS: Zea mays L., morpho-agronomic traits, production potential, morphologic response.

\section{INTRODUÇÃO}

O milho (Zea mays L.) caracteriza-se como uma gramínea pertencente à família Poaceae, com ampla empregabilidade, que vai desde a alimentação humana e animal, até como fonte de matéria-prima para a produção de biocombustíveis e elaboração de produtos processados, como embalagens biodegradáveis (ALVES et al. 2012). Estas características tornam este cereal uma das mais importantes culturas agrícolas do mundo.

O Brasil ocupa a terceira posição em produção desse cereal no cenário mundial, sendo superado por Estados Unidos e China. A produção brasileira na safra agrícola 2016/2017 foi de 97,7 milhões de toneladas 
(CONAB 2017). Nestas condições, a safrinha contribuiu com um volume de 67,1 milhões de toneladas produzidas, $67 \%$ do volume total do grão de milho produzido no país.

O milho destaca-se como a cultura que apresentou maior incremento em rendimento nas últimas décadas. Um dos principais motivos para este progresso produtivo consiste na descoberta da heterose (NARDINO et al. 2016). A necessidade crescente por grãos, acarreta em ações contínuas de pesquisas voltadas ao melhoramento genético da cultura e tecnologias de manejo nutricional e hídrico, visando incrementar a produtividade por ambiente de cultivo.

A evolução do melhoramento genético possibilitou o desenvolvimento de híbridos adaptados a semeaduras com altas densidades, fazendo com que os híbridos cultivados atualmente apresentem menor percentual de plantas sem espigas, maior sincronia floral e maior resposta ao adensamento, características que conferem tetos produtivos maiores em relação aos híbridos empregados no passado (SANGOI et al. 2002). Paralelo ao melhoramento genético clássico, a biotecnologia e a transgenia têm se mostrado como ferramentas complementares para o desenvolvimento de genótipos com características específicas, como a tolerância a herbicidas e insetos-praga. Liberada no Brasil na safra de 2008/2009 a tecnologia de transgênicos já ocupou em 2012 cerca de 73\% da área cultivada, evidenciando a importância de seu uso no desenvolvimento da agricultura nacional (PARENTONI et al. 2013).

A busca por híbridos adaptados e estáveis para cultivo em diferentes regiões e épocas de semeadura é uma das principais dificuldades aos programas de melhoramento genético de milho, principalmente quando considerada a alta manipulação gênica necessária para incorporação dos diferentes eventos tecnológicos existentes (STORCK et al. 2014). Esta dificuldade pode ser reduzida estratificando-se a região considerada em sub-regiões com características ambientais semelhantes, buscando genótipos específicos que se apresentem adaptados em tais ambientes (CARVALHO et al. 2002).

O conhecimento do desempenho produtivo dos híbridos de milho simples é importante para nortear quais genótipos podem ser utilizados em determinadas regiões produtoras de grãos, visando elucidar dúvidas quanto ao tipo de híbrido, o manejo e o nível tecnológico a ser utilizado (RIBEIRO \& ALMEIDA 2011). Os caracteres morfológicos que estão relacionados ao rendimento de grãos são fortemente influenciados pela interação dos genótipos por ambiente (ALMEIDA et al. 2003). Com isso, 0 desenvolvimento de genótipos adaptados, com alto rendimento para zonas específicas de produção, envolve a realização de ensaios em locais que representem fidedignamente as condições ambientais ali encontradas (NDHLELA et al. 2014).

A interação genótipo $x$ ambiente só pode ser detectada quando pelo menos dois genótipos são cultivados em dois ou mais ambientes (RAMALHO et al. 2012). Desta maneira o objetivo deste trabalho foi avaliar o comportamento dos caracteres morfológicos e de rendimento de grãos de híbridos simples de milho, para a Região Noroeste do estado do Rio Grande do Sul.

\section{MATERIAL E MÉTODOS}

Os experimentos foram realizados na safra agrícola 2014/2015, em três municípios do Noroeste do Rio Grande do Sul, sendo estes: Tenente Portela (Latitude $27^{\circ} 20^{\prime} 30,46$ 'S, Longitude $53^{\circ} 44^{\prime} 20.11^{\prime \prime O}$ e

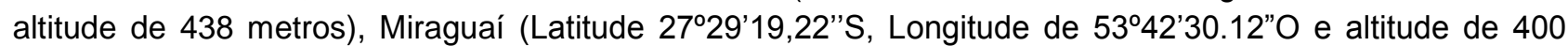
metros) e Vista Gaúcha (Latitude $27^{\circ} 15^{\prime} 17.11^{\prime \prime S}$, Longitude $53^{\circ} 45^{\prime} 24.92^{\prime \prime O}$ e altitude de 415 metros). O solo para todos os ambientes classifica-se como Latossolo Vermelho Distroférrico, e o clima é caracterizado por Köppen como Cfa subtropical úmido.

O delineamento experimental utilizado foi de blocos completos casualizados, organizados em esquema fatorial, três (ambientes de cultivo) $x$ sete (híbridos simples de milho), dispostos em três repetições, totalizando 63 unidades experimentais. Cada unidade experimental foi composta por quatro linhas de cinco metros de comprimento, espaçadas por 0,60 metros. As semeaduras foram realizadas dia 17/10/2014, 18/10/2014 e 19/10/2014 em Tenente Portela, Miraguaí, e Vista Gaúcha, respectivamente, em sistema direto, com adubação de base e cobertura estabelecidas de acordo com a necessidade da cultura. A densidade utilizada para todos os híbridos foi 75 mil plantas ha ${ }^{-1}$. Os híbridos simples de milho utilizados e suas características estão representados na Tabela 1. O controle de plantas invasoras foi realizado por meio do uso de herbicida recomendado para a cultura, visando o estabelecimento das plantas sem a ocorrência de mato competição.

A área útil considerada em cada unidade experimental caracterizou-se nas duas linhas centrais e desprezou-se 0,5 metro em cada extremidade para minimizar os efeitos de bordadura. Os caracteres agronômicos foram avaliados três plantas, escolhidas aleatoriamente, em cada unidade experimental, e mensurados de maneira similar a descrita por CARVALHO et al. (2014). Os caracteres avaliados foram: 
- Altura de planta (AP): determinada pela medida do nível do solo até o ápice da planta, resultados apresentados em centímetros.

- Altura de inserção da espiga (AIE): aferida do nível do solo até o nó de inserção da espiga, resultados apresentados em centímetros.

- Prolificidade (PRO): obtida pela razão entre o número de plantas da unidade experimental e o número de espigas evidenciadas, resultados apresentados em unidades.

- Diâmetro da espiga (DIES): aferido no terço médio da espiga, com auxílio de paquímetro digital, resultados apresentados em milímetros.

- Comprimento da espiga (CE): mensurado na extremidade basal até ápice da espiga, com auxílio de uma régua graduada, resultados apresentados em centímetros.

- Número de fileiras de grãos (NFG): contagem do número de fileiras de grãos na espiga, resultados apresentados em unidades.

- Número de grãos por fileira (NGFI): contagem do número de grãos por fileira da espiga da base até a extremidade da espiga, resultados apresentados em unidades.

- Massa da espiga (ME): a massa da espiga foi obtida com o auxílio de uma balança de precisão, resultados apresentados em gramas.

- Diâmetro do sabugo (DS): mensurado no terço médio do sabugo com auxílio de um paquímetro digital, resultados apresentados em milímetros.

- Massa do sabugo (MS): a massa do sabugo foi obtida com o auxílio de uma balança de precisão, resultados apresentados em gramas.

- Massa de grãos por espiga (MGE): após debulha manual determinou-se a massa de grãos de cada espiga em balança de precisão, os resultados obtidos foram corrigidos para $13 \%$ de umidade, resultados apresentados em gramas.

- Massa de mil grãos (MMG): caráter determinado por meio da amostragem de oito repetições com 100 grãos, por unidade experimental, posteriormente determinou-se a massa de cada subamostra, e os dados obtidos foram corrigidos para $13 \%$ de umidade, resultados em gramas.

- Rendimento de grãos (RG): caráter obtido pela razão entre a massa total de grãos da unidade experimental e o número de plantas na colheita, desta maneira a massa de grãos por planta foi ajustada para $13 \%$ de umidade (base úmida), posteriormente os dados foram ajustados para densidade populacional, e resultados apresentados em tha-1.

Tabela 1. Híbridos de milho utilizados no experimento e suas características quanto à base genética e classificação por ciclo de maturação.

Table 1. Corn hybrids used in the experiment and their characteristics regarding genetic basis and classification by maturation cycle.

\begin{tabular}{lll}
\hline Híbridos & Base Genética & Classificação/ciclo \\
\hline P 1630 HX & Híbrido Simples & Hiperprecoce \\
DKB 230 PRO 3 & Híbrido Simples & Hiperprecoce \\
DKB 240 PRO 2 & Híbrido Simples & Superprecoce \\
DKB 240 PRO 3 & Híbrido Simples & Superprecoce \\
DKB 250 PRO 2 & Híbrido Simples & Precoce \\
DKB 290 PRO 3 & Híbrido Simples & Precoce \\
DKB 315 PRO 3 & Híbrido Simples & Superprecoce \\
\hline
\end{tabular}

Os dados obtidos foram preliminarmente analisados quanto a presença de outliers e submetidos ao teste de normalidade e homogeneidade de variâncias por Hartley. Atendidas estas pressuposições, procedeu-se a análise de variância conjunta por meio do teste $F(p<0,05)$. Os caracteres que apresentaram interação significativa entre ambientes de cultivo $\mathrm{x}$ híbridos simples de milho foram comparados aos efeitos simples para cada fator de variação. Os caracteres com ausência de interação significativa foram comparados aos efeitos principais pelo teste Tukey a $5 \%$ de probabilidade de erro. Para a realização das análises utilizou-se o software estatístico Genes (CRUZ 2013).

\section{RESULTADOS E DISCUSSÃO}

O resultado da análise de variância (Tabela 2) mostrou efeito significativo $(p<0,05)$ para interação ambientes de cultivo $x$ híbridos simples de milho para os caracteres DIES, NGFI, DS, MGE e RG. Foram 
comparados os efeitos principais para os caracteres AP, AIE, PRO, CE, NFG, ME, MS e MMG. Os coeficientes de variação apresentaram baixos valores, onde apenas a PRO, ME e MGE apresentaram valores acima de $10 \%$ (Tabela 2). Isto é boa precisão experimental, permitindo a inferência aos resultados com maior confiança.

Tabela 2. Quadrados médios obtidos pela análise de variância para os caracteres altura de planta (AP), altura de inserção da espiga (AIE), prolificidade (PRO), diâmetro da espiga (DIES), comprimento da espiga (CE), número de fileira de grãos (NFG), número de grãos por fileira (NGFI), massa da espiga (ME), diâmetro do sabugo (DS), massa do sabugo (MS), massa de grãos por espiga (MGE), massa de mil grãos (MMG) e rendimento de grãos (RG), de híbridos de milho cultivados em diferentes locais da Região Noroeste do estado do Rio Grande do Sul.

Table 2. Mean squares obtained by analysis of variance for the characteristics plant height $(\mathrm{PH})$, ear insertion height $(E I H)$, prolificacy $(P R O)$, ear diameter $(E D)$, ear length $(E L)$, number of grain rows per cob (NGR), number of grains per row (NGPR), ear mass (EM), cob diameter (CD), cob mass $(C M)$, grain mass per ear (GME) thousand-grain mass (TGM) and grain yield (GY) of corn hybrids grown at different locations in the Northwest region of the state of Rio Grande do Sul.

\begin{tabular}{|c|c|c|c|c|c|c|c|c|}
\hline \multirow{2}{*}{ Fonte de Variação } & \multirow{2}{*}{$\mathrm{GL}$} & \multicolumn{7}{|c|}{ Quadrado médio } \\
\hline & & $\mathrm{AP}$ & AIE & PRO & DIES & $\mathrm{CE}$ & NFG & NGFI \\
\hline Local & 2 & $2,18^{* *}$ & $0,32^{* *}$ & $0,08^{*}$ & $16,73^{*}$ & $26,11^{\star *}$ & $1,15^{\mathrm{ns}}$ & $141,81^{* *}$ \\
\hline Híbrido & 6 & $0,13^{* *}$ & $0,17^{* *}$ & $0,50^{* *}$ & $113,79^{\star *}$ & $1,60^{\text {ns }}$ & $25,56^{\star *}$ & $14,91^{\mathrm{ns}}$ \\
\hline Local*Híbrido & 12 & $0,01^{\mathrm{ns}}$ & $0,02^{\text {ns }}$ & $0,02^{\text {ns }}$ & $6,42^{\star \star}$ & $1,74^{\mathrm{ns}}$ & $0,91^{\mathrm{ns}}$ & $20,01^{* *}$ \\
\hline Bloco & 2 & $0,00^{\text {ns }}$ & $0,00^{\text {ns }}$ & $0,01^{\mathrm{ns}}$ & $1,13^{\text {ns }}$ & 0,21 & $0,53^{\text {ns }}$ & $10,11^{\mathrm{ns}}$ \\
\hline \multirow[t]{2}{*}{ CV (\%) } & & 4,91 & 7,72 & 11,44 & 3,01 & 6,84 & 6,65 & 6,69 \\
\hline & & $\mathrm{ME}$ & DS & MS & MGE & MMG & $R G$ & \\
\hline Local & 2 & $6049,36^{\star \star}$ & $0,138^{\text {ns }}$ & $14,26^{\star \star}$ & $8147,16^{* *}$ & $1211,19^{\text {ns }}$ & $61,98^{* *}$ & \\
\hline Híbrido & 6 & $10416,78^{\star *}$ & $55,80^{\star *}$ & $32,81^{* *}$ & $4867,26^{\star *}$ & $7414,16^{\star *}$ & $35,02^{* *}$ & \\
\hline Local*Híbrido & 12 & $1440,17^{\mathrm{ns}}$ & $4,58^{* *}$ & $5,85^{\text {ns }}$ & $1321,01^{*}$ & $666,32^{\text {ns }}$ & $5,84 * *$ & \\
\hline Bloco & 2 & $0,23^{\text {ns }}$ & $0,39^{\text {ns }}$ & $0,33^{\text {ns }}$ & $316,85^{\text {ns }}$ & $1217,10^{\text {ns }}$ & $1,22^{\text {ns }}$ & \\
\hline$\overline{C V}(\%)$ & & 11,05 & 4,65 & 4,60 & 11,45 & 6,94 & 8,85 & \\
\hline
\end{tabular}

${ }^{\star *} \mathrm{e}^{*}$ significativo a 1 e $5 \%$ de probabilidade de erro respectivamente pelo teste $\mathrm{F}$; ${ }^{\text {ns }}$ não significativo.

No caráter diâmetro da espiga (DIES) observou-se que híbrido DKB 290 PRO $3^{\circledR}, \mathrm{P} 1630 \mathrm{HX}{ }^{\circledR}$ e DKB 315 PRO $3^{\circledR}$, cultivados em Miraguaí, RS, expressaram maior valor (Tabela 3). Os híbridos DKB 230 PRO $3^{\circledR}$, DKB 240 PRO $2^{\circledR}$ e DKB 250 PRO $2^{\circledR}$, não diferiram entre si, apresentando DIES intermediário, enquanto que o híbrido DKB 240 PRO $3^{\circledR}$ apresentou o menor DIES. Em Tenente Portela, RS, os híbridos DKB 290 PRO $3^{\circledR}, \mathrm{P} 1630 \mathrm{HX}{ }^{\circledR}$ e DKB 315 PRO $3^{\circledR}$ expressaram maior magnitude. Estes também não diferiram dos demais, que apresentaram menores DIES. Para Vista Gaúcha, RS, o comportamento dos híbridos mantiveram-se semelhante à Miraguaí, RS e Tenente Portela, RS, onde o DIES foi influenciado pela expressão do genótipo e sofreu pouca influência do ambiente. O híbrido DKB 290 PRO $3^{\circledR}$ apresentou a maior média de DIES nos três ambientes (Tabela 3). Os resultados estão de acordo com CARVALHO et al. (2014), que avaliaram o desempenho agronômico de híbridos simples de milho em ambiente irrigado e sequeiro e não observaram diferenças significativas para DIES entre os ambientes. Caracteres que expressam pouca alteração quando comparados em diferentes ambientes e que estejam correlacionados com componentes agronômicos de interesse, como o rendimento de grãos, podem ser utilizados como critério de seleção indireta na busca por genótipos superiores em programas de melhoramento genético.

O número de grãos por fileira (NGFI) está diretamente relacionado com o comprimento médio da espiga, sendo que sua magnitude depende da interação entre híbridos e ambientes (VILELA et al. 2012). Comparando o efeito do ambiente na expressão do NGFI, observa-se que no ambiente de cultivo Miraguaí, RS expressou as menores magnitudes para os híbridos DKB 240 PRO $2^{\circledR}$, DKB 240 PRO $3^{\circledR}$ e DKB 290 PRO $3^{\circledR}$ (Tabela 4). Para Tenente Portela, RS e Vista Gaúcha, RS, não foram observadas diferenças estatísticas no caráter NGFI. Ao avaliar o comportamento do NGFI entre os híbridos, observou-se que a magnitude do NGFI observada em Miraguaí, RS (Tabela 4), não diferenciou estatisticamente entre os híbridos P $1630 \mathrm{HX}{ }^{\circledR}$, DKB 230 PRO $3^{\circledR}$, DKB 240 PRO $3^{\circledR}, 250$ PRO $2^{\circledR}$ e DKB 315 PRO $3^{\circledR}$, sendo as menores magnitudes observadas nos híbridos DKB 240 PRO $2^{\circledR}$ e DKB 290 PRO $3^{\circledR}$. O maior NGFI médio foi observado para Tenente Portela (Tabela 4). 
Menores NGFI resultam em espigas com menor número de grãos, o que pode ser prejudicial ao potencial produtivo do híbrido (SANGOI et al. 2010). Os estádios fenológicos compreendidos entre V4 (quatro folhas expandidas) e V9 (nove folhas expandidas) expressam grande importância para a cultura, pois neste período são definidos os componentes de rendimento intrínsecos às espigas em genótipos de milho, como o número de fileiras de grãos e o número de grãos por fileira, respectivamente.

Tabela 3. Diâmetro da espiga (DIES) de híbridos de milho cultivados em diferentes locais da Região Noroeste do estado do Rio Grande do Sul.

Table 3 Ear diameter (ED) of corn hybrids grown at different locations in the Northwest region of the state of Rio Grande do Sul.

\begin{tabular}{|c|c|c|c|}
\hline \multirow{2}{*}{ Híbridos } & \multicolumn{3}{|c|}{ Ambientes de cultivo } \\
\hline & Miraguaí, RS & Tenente Portela, RS & Vista Gaúcha, RS \\
\hline & --- & ----- mm ----- & ------ \\
\hline P $1630 H X^{\circledR}$ & $52,69 a b A$ & $53,92 \mathrm{ab} A$ & $52,00 \mathrm{bc} A$ \\
\hline DKB 230 PRO $3^{\circledR}$ & $48,62 \mathrm{bc} \mathrm{A}$ & 49,61 bc $A$ & $47,03 \mathrm{~d} A$ \\
\hline DKB 240 PRO $2^{\circledR}$ & 47,50 c A & $49,35 \mathrm{bc} \mathrm{A}$ & $47,75 \mathrm{~cd} \mathrm{~A}$ \\
\hline DKB 240 PRO $3^{\circledR}$ & $42,50 \mathrm{~d} \mathrm{~B}$ & 47,86 bc A & $45,49 \mathrm{~d} A$ \\
\hline DKB 250 PRO $2^{\circledR}$ & $47,25 \mathrm{c} \mathrm{A}$ & $46,77 \mathrm{bc} \mathrm{A}$ & $46,87 \mathrm{~d} A$ \\
\hline DKB 290 PRO $3^{\circledR}$ & 53,44 a $A$ & 55,41 a $A$ & 57,43 a $A$ \\
\hline DKB 315 PRO $3^{\circledR}$ & 49,72 abc $A$ & $50,90 \mathrm{ab} A$ & $53,31 a b$ A \\
\hline
\end{tabular}

CV (\%) 3,01

Médias seguidas pela mesma letra minúscula na coluna para híbridos e maiúscula na linha, para ambientes, não diferem estatisticamente pelo teste de Tukey a $5 \%$ de significância.

Condições ambientais desfavoráveis, como déficit hídrico ou nutricional entre estes estádios podem comprometer o potencial produtivo dos híbridos (BASI 2013). Estudos realizados por SANTOS \& CARLESSO (1998), enfatizam que a cultura do milho é relativamente tolerante ao estresse hídrico durante seu estádio vegetativo, contudo demonstra grande sensibilidade, apresentando decréscimo no rendimento de grãos, se a deficiência hídrica ocorrer entre as fases de fertilização e enchimento de grãos. Os resultados contrastantes para NGFI dos híbridos $\mathrm{P} 1630 \mathrm{HX}{ }^{\circledR}$ e DKB 290 PRO $3^{\circledR}$ observados apenas em Miraguaí, RS, comprovam a influência do ambiente de cultivo na resposta diferenciada de cada híbrido, principalmente devido a estes híbridos serem os mais contrastantes em ciclo, logo, apresentando o período crítico para condições desfavoráveis, temporalmente distantes.

Tabela 4. Número de grãos por fileira (NGFI) de híbridos de milho cultivados em diferentes locais da Região Noroeste do estado do Rio Grande do Sul.

Table 4. Number of grains per row (NGPR) of corn hybrids grown at different locations in the Northwest region of the state of Rio Grande do Sul.

\begin{tabular}{lccc}
\hline Híbridos & \multicolumn{3}{c}{ Ambientes de cultivo } \\
\cline { 2 - 4 } & \multicolumn{1}{c}{ Miraguaí, RS } & Tenente Portela, RS & Vista Gaúcha, RS \\
\hline P 1630 HX® & 38,44 a A & 40,66 a A & 34,33 a A \\
DKB 230 PRO 3 & 36,22 ab A & 38,55 a A & 34,66 a A \\
DKB 240 PRO 2 & 28,77 b B & 41,66 a A & 35,77 a A \\
DKB 240 PRO 3 & 31,33 ab B & 39,33 a A & 37,11 a A \\
DKB 250 PRO 2 & 34,06 ab A & 37,55 a A & 37,00 a A \\
DKB 290 PRO 3 & 30,22 b B & 36,26 a A & 34,33 a A \\
DKB 315 PRO 3 & 36,66 ab A & 37,55 a A & 35,22 a A \\
\hline CV $(\%)$ & $7,83 ~$ & &
\end{tabular}

CV (\%) 7,83
Médias seguidas pela mesma letra minúscula na coluna para híbridos e maiúscula na linha, para ambientes, não diferem
estatisticamente pelo teste de Tukey a $5 \%$ de significância.

O comportamento do caráter diâmetro do sabugo (DS) (Tabela 5), apresentou pouca variação entre os ambientes de cultivo, contudo efeitos contrastantes são observados entre os híbridos. Os resultados indicam que o híbrido DKB 290 PRO $3^{\circledR}$ apresentou o maior DS nos três ambientes, apresentando a maior média de DS entre os híbridos estudados (Tabela 5). Híbridos com menores dimensões do sabugo apresentam maior capacidade de perda de água pelos grãos durante a maturação, o que pode beneficiar o sistema produtivo já que estes passam menos tempo no campo, estão menos propensos a ocorrência de 
pragas e patógenos (GUISCEM et al. 2002).

Tabela 5. Diâmetro do sabugo (DS) de híbridos de milho cultivados em diferentes locais da Região Noroeste do estado do Rio Grande do Sul.

Table 5. Cob diameter (CD) of corn hybrids grown at different locations in the Northwest region of the state of Rio Grande do Sul.

\begin{tabular}{lccc}
\hline Híbridos & \multicolumn{3}{c}{ Ambientes de cultivo } \\
\cline { 2 - 4 } & Miraguaí, RS & Tenente Portela, RS & Vista Gaúcha, RS \\
\hline P 1630 HX & 25,83 ab A & 26,31 bc A & 25,48 b A \\
DKB 230 PRO 3 & 27,04 ab A & 26,20 bc A & 23,06 b B \\
DKB 240 PRO 2 & 25,93 ab A & 25,45 bc A & 25,42 b A \\
DKB 240 PRO 3 & 24,14 b A & 25,63 bc A & 23,92 b A \\
DKB 250 PRO 2 & 24,64 b A & 23,87 bc A & 24,83 b A \\
DKB 290 PRO 3 & 29,60 a A & 30,70 a A & 32,98 a A \\
DKB 315 PRO 3 & 28,62 a A & 28,41 ab A & 29,81 a A \\
\hline CV (\%) & 4,65 & &
\end{tabular}

Médias seguidas pela mesma letra minúscula na coluna para híbridos e maiúscula na linha, para ambientes, não diferem estatisticamente pelo teste de Tukey a $5 \%$ de significância.

A massa de grãos por espiga (MGE) apresenta-se como um dos principais componentes de rendimento do milho, juntamente com o número de espigas por unidade de área e a massa de mil grãos (BERGAMASCHI et al. 2006). A MGE em Miraguaí, RS expressou maior magnitude para o híbrido P1630 $\mathrm{Hx}^{\circledR}$ (Tabela 6), sendo estatisticamente superior aos híbridos DKB 240 PRO $2^{\circledR}$ e DKB 240 PRO $3^{\circledR}$. Para Tenente Portela, RS e Vista Gaúcha, RS, o comportamento dos híbridos foi similar, apresentando Tenente Portela, RS, a maior média de MGE (Tabela 6).

Tabela 6. Massa de grãos por espiga (MGE) de híbridos de milho cultivados em diferentes locais da Região Noroeste do estado do Rio Grande do Sul.

Table 6. Grain mass per ear (GME) of corn hybrids grown at different locations in the Northwest region of the state of Rio Grande do Sul.

\begin{tabular}{lccc}
\hline Híbrido & \multicolumn{3}{c}{ Ambientes de cultivo } \\
\cline { 2 - 4 } & \multicolumn{1}{c}{ Miraguaí, RS } & Tenente Portela, RS & Vista Gaúcha, RS \\
\hline P 1630 HX & 243,62 a A & 277,18 a A & 202,60 a A \\
DKB 230 PRO 3 & 200,17 ab A & 225,93 a A & 200,19 a A \\
DKB 240 PRO 2 & 164,62 b B & 244,98 a A & 188,78 a AB \\
DKB 240 PRO 3 & 154,26 b A & 219,72 a A & 184,76 a A \\
DKB 250 PRO 2 & 198,66 ab A & 217,88 a A & 204,96 a A \\
DKB 290 PRO 3 & 224,77 ab A & 255,54 a A & 277,15 a A \\
DKB 315 PRO 3 & 204,05 ab A & 222,58 a A & 232,77 a A \\
\hline CV (\%) & 11,45 &
\end{tabular}

Médias seguidas pela mesma letra minúscula na coluna para híbridos e maiúscula na linha, para ambientes, não diferem estatisticamente pelo teste de Tukey a $5 \%$ de significância.

Híbridos com diferentes ciclos de maturação no mesmo ambiente apresentam períodos críticos diferentes, de modo que o estresse hídrico pode apresentar-se mais severo para os distintos genótipos. SERPA et al. (2012) citam que a redução na massa de grãos por espiga é atribuída ao aumento da competição intraespecífica pelos recursos hídricos e nutricionais. Caso o estresse hídrico ocorra na fase de definição do número de grãos por fileira, os híbridos que estão definindo este componente podem sofrer maiores efeitos, prejudicando seu potencial produtivo.

A definição do potencial de rendimento de grãos (RG) em híbridos de milho é intrínseca ao material genético e sua interação com o ambiente de cultivo, sendo influenciado pelo sistema de manejo (CARGNELUTTI FILHO et al. 2007). Observa-se na Tabela 7, que o ambiente de cultivo expressou influência no RG. Em Miraguaí, RS, os híbridos P $1630 \mathrm{HX}{ }^{\circledR}$, DKB 290 PRO $3^{\circledR}$ e DKB 315 PRO $3^{\circledR}$ apresentaram os maiores RG, diferindo apenas do híbrido DKB 240 PRO $3^{\circledR}$. Em Tenente Portela, RS, o comportamento dos híbridos quanto ao RG diferiu de Miraguaí, RS. Os híbridos $\mathrm{P} 1630 \mathrm{HX}{ }^{\circledR}, \mathrm{DKB} 240 \mathrm{PRO}$ $2^{\circledR}$, DKB 290 PRO $3^{\circledR}$ e DKB 315 PRO $3^{\circledR}$ apresentaram os maiores rendimentos. Em Vista Gaúcha, RS, os 
híbridos DKB 290 PRO $3^{\circledR}$ e DKB 315 PRO $3^{\circledR}$ apresentaram o maior RG. Os resultados médios apontaram os híbridos DKB 290 PRO $3^{\circledR}$ e DKB 315 PRO $3^{\circledR}$ como os mais produtivos. Entre locais, Tenente Portela, RS apresentou maior RG (Tabela 7). A resposta diferenciada do $R G$ em híbridos cultivados em diferentes ambientes também foi evidenciada por diversos autores (ARGENTA et al. 2003, COSTA et al. 2010, CARDOSO et al. 2012, CARVALHO et al. 2014), possibilitando inferir a instabilidade do caráter. Fatores bióticos e abióticos expressam grande influência ao $R G$, sendo que a sazonalidade hídrica se caracteriza como uma das principais dificuldades no planejamento da semeadura.

Tabela 7. Rendimento de grãos $(R G)$ de híbridos de milho cultivados em diferentes locais da Região Noroeste do estado do Rio Grande do Sul.

Table 7. Grain yield (GY) of corn hybrids grown at different locations in the Northwest region of the state of Rio Grande do Sul.

\begin{tabular}{lccc}
\hline Híbridos & \multicolumn{3}{c}{ Ambientes de cultivo } \\
\cline { 2 - 4 } & Miraguaí, RS & Tenente Portela, RS & Vista Gaúcha, RS \\
\hline P 1630 HX & $14,33 \mathrm{a} \mathrm{B}$ & $18,63 \mathrm{a} \mathrm{A}$ & $11,70 \mathrm{bc} \mathrm{B}$ \\
DKB 230 PRO 3 & $12,33 \mathrm{ab} \mathrm{A}$ & $13,55 \mathrm{c} \mathrm{A}$ & $10,81 \mathrm{c} \mathrm{A}$ \\
DKB 240 PRO 2 & $11,49 \mathrm{ab} \mathrm{A}$ & $15,17 \mathrm{abc} \mathrm{A}$ & $11,94 \mathrm{bc} \mathrm{A}$ \\
DKB 240 PRO 3 & $9,81 \mathrm{~b} \mathrm{~B}$ & $13,90 \mathrm{bc} \mathrm{A}$ & $10,49 \mathrm{c} \mathrm{A}$ \\
DKB 250 PRO 2 & $11,13 \mathrm{ab} \mathrm{A}$ & $13,62 \mathrm{c} \mathrm{A}$ & $10,56 \mathrm{c} \mathrm{A}$ \\
DKB 290 PRO 3 & $14,53 \mathrm{a} \mathrm{B}$ & $17,46 \mathrm{ab} \mathrm{AB}$ & $19,13 \mathrm{a} \mathrm{A}$ \\
DKB 315 PRO 3 & $14,06 \mathrm{a} \mathrm{A}$ & $16,41 \mathrm{abc} \mathrm{A}$ & $15,33 \mathrm{ab} \mathrm{A}$ \\
\hline CV $(\%)$ & 8,85 & &
\end{tabular}

CV (\%)

Médias seguidas pela mesma letra minúscula na coluna para híbridos e maiúscula na linha, para ambientes, não diferem estatisticamente pelo teste de Tukey a 5\% de significância.

Pesquisas indicam que a altura de planta (AP) é uma característica resultante da interação da composição genética com os ambientes de cultivo e sistemas de manejo, onde sua correlação com os componentes de rendimento como comprimento da espiga e número de grãos por fileira podem assumir distintos sentidos (DOURADO NETO 2003). As maiores magnitudes na altura de planta (AP) foram observadas em Vista Gaúcha, RS, atingindo 2,46 m (Tabela 8). Os resultados possibilitam inferir que há influência do ambiente na expressão do caráter, pois o sistema de cultivo foi semelhante em todos os locais. Os resultados confirmam as pesquisas de CARVALHO et al. (2014), onde evidenciaram maiores alturas de planta em híbridos de milho quando cultivados em sistema sequeiro. Ao avaliar-se a magnitude do caráter entre os híbridos, observa-se uma diferença de 0,41 m entre o híbrido que apresentou maior AP (DKB 240 PRO $2^{\circledR}$ ) e menor AP (DKB 315 PRO $3^{\circledR}$ ).

A altura de inserção da espiga (AIE), sofre influência do ambiente de cultivo e da densidade de semeadura, assim maiores AIE são observadas em maiores densidades de semeaduras (PENARIOL 2003), efeito causado pela dominância apical do pendão (SANGOI et al. 2011). Os dados evidenciam que o caráter AIE foi influenciado pelas condições ambientais. Quando comparados os ambientes de cultivo, observa-se que a menor magnitude foi observada em Miraguaí, RS e maior em Tenente Portela, RS (Tabela 8). Ao comparar os diferentes híbridos, observa-se uma diferença de $0,2 \mathrm{~m}$ entre o híbrido mais alto (DKB 240 PRO $2^{\circledR}$ ) e o mais baixo (DKB 315 PRO $3^{\circledR}$ ).

A prolificidade (PRO) no milho é caracterizada pela capacidade de uma planta produzir mais de uma espiga (SANGOI et al. 2010). Comparando os diferentes ambientes de cultivo, observa-se que Tenente Portela, RS e Vista Gaúcha, RS apresentaram diferenças significativas, sendo Vista Gaúcha, RS superior (Tabela 8). Este resultado pode estar associado as maiores alturas de plantas em Vista Gaúcha, RS, favorecendo a emissão da segunda espiga. Esta associação foi observada por CHURATA \& AYLA-OSUNA (1996), onde evidenciaram alta correlação genética $(r=0,714)$, entre PRO com AP. Em relação aos híbridos, o DKB 240 PRO $3^{\circledR}$ e DKB 250 PRO $2^{\circledR}$, foram os mais prolíferos (Tabela 8). A menor PRO foi evidenciada para os híbridos DKB 315 PRO $3^{\circledR}$, DKB 290 PRO $3^{\circledR}$ e P $1630 \mathrm{HX}^{\circledR}$.

Ao comparar o rendimento de grãos destes híbridos, observa-se que os híbridos mais prolíferos apresentam menor rendimento de grãos. Tal resultado pode ser explicado devido aos híbridos menos prolíferos apresentarem maior massa de espiga, na densidade empregada no experimento (Tabela 8). Comportamento divergente entre PRO e massa de espiga também foi evidenciada por LOPES et al. (2007). No entanto, em pesquisa realizada por SANGOI et al. (2010), avaliando a influência do afilhamento e da prolificidade como características estabilizadoras do rendimento de grãos de milho, indicam que a PRO não 
afeta o rendimento de grãos.

Tabela 8. Médias para os caracteres altura de planta (AP), altura de inserção da espiga (AIE), prolificidade (PRO), comprimento de espiga (CE), número de fileiras de grãos (NFG), massa da espiga (ME), massa do sabugo, (MS) e massa de mil grãos (MMG) de híbridos de milho cultivados em diferentes locais da Região Noroeste do estado do Rio Grande do Sul.

Table 8. Means for the characteristics plant height $(P H)$, ear insertion height $(E I H)$, prolificacy $(P R O)$, ear length (EL), number of grain rows (NGR), ear mass (EM) and thousand-grains mass (TGM) of corn hybrids grown at different locations in the Northwest region of the state of Rio Grande do Sul.

\begin{tabular}{|c|c|c|c|c|c|c|c|c|}
\hline & AP & AIE & PRO & CE & NFG & ME & MS & MMG \\
\hline \multicolumn{9}{|c|}{ Ambientes.. } \\
\hline Miraguaí, RS & $1,83 \mathrm{c}$ & $0,87 c$ & $1,15 a b$ & $18,97 \mathrm{a}$ & $15,74 \mathrm{a}$ & 246,02 b & $25,05 \mathrm{~b}$ & $337,34 \mathrm{a}$ \\
\hline Tenente Portela, RS & $2,28 \mathrm{~b}$ & $1,12 \mathrm{a}$ & $1,12 \mathrm{~b}$ & $19,36 \mathrm{a}$ & $15,39 \mathrm{a}$ & 276,84 a & $26,11 a b$ & $351,93 \mathrm{a}$ \\
\hline Vista Gaúcha, RS & $2,46 \mathrm{a}$ & $1,04 \mathrm{~b}$ & $1,24 \mathrm{a}$ & $17,26 \mathrm{~b}$ & $15,30 \mathrm{a}$ & 249,09 b & 26,67 a & $348,36 \mathrm{a}$ \\
\hline & & & .....Híbrio & & & & 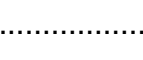 & $\cdots$ \\
\hline P $1630 H X^{\circledR}$ & $2,30 a b$ & $0,77 \mathrm{~d}$ & $0,96 \mathrm{c}$ & $18,64 \mathrm{a}$ & $18,66 \mathrm{a}$ & $266,30 \mathrm{bc}$ & $25,95 \mathrm{bc}$ & $332,26 \mathrm{~b}$ \\
\hline DKB 230 PRO $3^{\circledR}$ & $2,11 \mathrm{c}$ & $0,94 \mathrm{c}$ & $1,07 \mathrm{bc}$ & $18,82 \mathrm{a}$ & $14,96 \mathrm{c}$ & 250,46 bc & $26,11 \mathrm{bc}$ & $345,56 \mathrm{~b}$ \\
\hline DKB 240 PRO $2^{\circledR}$ & $2,34 \mathrm{a}$ & $1,13 a b$ & $1,24 \mathrm{~b}$ & $18,18 \mathrm{a}$ & $14,74 \mathrm{c}$ & 228,33 bc & $25,05 \mathrm{~cd}$ & $325,67 b$ \\
\hline DKB 240 PRO $3^{\circledR}$ & $2,23 a b c$ & $1,09 a b$ & $1,44 \mathrm{a}$ & $18,14 \mathrm{a}$ & $13,70 \mathrm{c}$ & $222,03 \mathrm{c}$ & $24,06 \mathrm{~cd}$ & $317,01 \mathrm{~b}$ \\
\hline DKB 250 PRO $2^{\circledR}$ & 2,18 bc & $1,02 \mathrm{bc}$ & $1,53 \mathrm{a}$ & $18,68 \mathrm{a}$ & $14,59 \mathrm{c}$ & $242,49 \mathrm{bc}$ & $23,69 d$ & $344,93 \mathrm{~b}$ \\
\hline DKB 290 PRO $3^{\circledR}$ & $2,18 \mathrm{bc}$ & $1,17 \mathrm{a}$ & $1,03 \mathrm{c}$ & $19,19 a$ & $16,81 b$ & 323,63 a & $28,90 \mathrm{a}$ & $404,97 \mathrm{a}$ \\
\hline DKB 315 PRO $3^{\circledR}$ & $1,93 \mathrm{~d}$ & $0,93 \mathrm{c}$ & $0,93 \mathrm{c}$ & $18,07 \mathrm{a}$ & $14,88 \mathrm{c}$ & $268,00 \mathrm{~b}$ & $27,85 a b$ & $350,63 \mathrm{~b}$ \\
\hline Média & 2,19 & 1,01 & 1,17 & 18,52 & 15,48 & 257,32 & 25,95 & 345,86 \\
\hline CV (\%) & 5,18 & 9,08 & 11,53 & 6,91 & 6,54 & 12,00 & 6,03 & 7,07 \\
\hline
\end{tabular}

Médias seguidas da mesma letra minúscula na coluna não diferem estatisticamente pelo teste de Tukey a $5 \%$ de significância.

Ao avaliar o comprimento da espiga (CE) nos diferentes locais de cultivo, observou-se que Vista Gaúcha, RS apresentou menor valor (Tabela 8). Uma pesquisa indicou existência de associação positiva entre CE e caracteres de interesse agronômico como massa de grãos por espiga $(r=0,442)$ e massa de mil grãos ( $r=0,424)$ (LOPES et al. 2007). Contudo, este caráter sofre grande influência do ambiente de cultivo (SILVA et al. 1999, DOURADO-NETO 2003). Quando comparada a expressão do caráter entre os híbridos, não se observam diferenças estatísticas, fato que pode estar relacionado à uniformidade das espigas, geralmente observadas em híbridos simples.

O número de fileiras de grãos (NFG) se apresentou semelhante para os locais (Tabela 8). Entre os híbridos, a maior magnitude foi observada para $P 1630 \mathrm{HX}{ }^{\circledR}$, seguido de DKB 290 PRO $3^{\circledR}$. Visando o incremento no rendimento, é importante ressaltar que a seleção baseada em uma única característica pode ocasionar problemas, principalmente se esta não for diretamente relacionada com o interesse. No caso do NFG, pesquisas com híbridos simples, indicaram que seu aumento resulta em maior número de grãos por espiga, contudo estes grãos tendem a apresentar menor massa específica (LOPES et al. 2007).

A massa da espiga (ME) (Tabela 8) apresentou maior magnitude para Tenente Portela, RS. Entre os híbridos, a maior magnitude foi observada para DKB 290 PRO $3^{\circledR}$. Para a massa do sabugo (MS), a maior magnitude foi observada em Vista Gaúcha, RS, ao passo que em Miraguaí, RS, mostrou-se inferior (Tabela 8). Entre os híbridos, superioridade é atribuída para os híbridos DKB 290 PRO $3^{\circledR}$ e DKB 315 PRO $3^{\circledR}$ (Tabela 8).

Em híbridos simples, há uma associação linear positiva da MS com RG, contudo, quando avaliadas as relações de causa e efeito, é observado que o efeito indireto positivo via massa de mil grãos, é o responsável por tal associação (LOPES et al. 2007). Tal característica está estreitamente relacionada com a dinâmica de distribuição de fotoassimilados nas plantas, a qual pode ser prejudicada por diversos fatores ambientais como água, luz e temperatura (LEMOINE et al. 2013).

Estudos elencam a massa de mil grãos (MMG) como um dos caracteres determinantes ao potencial de rendimento de um híbrido, podendo ser utilizada na seleção indireta, visando incremento no rendimento (NATARAJ et al. 2014, KUMAR et al. 2015). A MMG não expressou diferença estatística entre diferentes locais de cultivo. Ao elucidar a magnitude do caráter entre os híbridos, se observou que o híbrido com maior MMG foi o DKB 290 PRO $3^{\circledR}$ (Tabela 8). Os dados possibilitam inferir comportamento estável do caráter diante dos diferentes ambientes de cultivo, estando de acordo com a literatura, onde pesquisas, concluíram que este caráter sofre poucos efeitos das condições ambientais (LOPES et al. 2007). 


\section{CONCLUSÃO}

Os híbridos DKB 290 PRO $3^{\circledR}$ e DKB 315 PRO $3^{\circledR}$ apresentaram as maiores produtividades na média dos ambientes estudados. O híbrido DKB 290 PRO $3^{\circledR}$ se mostrou superior para os caracteres altura de inserção de espiga, massa de espiga, massa do sabugo e massa de mil grãos entre os híbridos estudados, e concomitante ao DKB 315 PRO $3^{\circledR}$, maiores rendimentos de grãos.

Para o caráter massa de grãos por espiga, somente no ambiente Miraguaí, RS, o híbrido P $1630 \mathrm{HX}{ }^{\circledR}$ se mostrou superior aos demais genótipos. A altura de planta e a prolificidade manifestaram maiores magnitudes no ambiente Vista Gaúcha, RS. Já a maior altura de inserção de espiga, número de grãos por fileira, massa da espiga, massa de grãos por espiga e rendimento de grãos foram obtidas em Tenente Portela, RS.

\section{REFERÊNCIAS}

ALMEIDA ML et al. 2003. Crescimento inicial de milho e sua relação com o rendimento de grãos. Ciência Rural 33: 189194.

ALVES JO et al. 2012. Síntese de nano materiais de carbono a partir de resíduos de milho (DDGS). Química Nova 35: 1534-1537.

ARGENTA G et al. 2003. Potencial de rendimento de grãos de milho em dois ambientes e cinco sistemas de produção. Scientia Agraria 4: 27-34.

BASI S. 2013. Associação de Azospirillum brasilense e de nitrogênio em cobertura na cultura do milho. Dissertação (Mestrado em Agronomia). Guarapuava: UNICENTRO. 50p.

BERGAMASCHI H et al. 2006. Déficit hídrico e produtividade na cultura do milho. Pesquisa Agropecuária Brasileira 41: 243-249.

CARDOSO MJ et al. 2012. Identificação de cultivares de milho com base na análise de estabilidade fenotípica no MeioNorte brasileiro. Revista Ciência Agronômica 43: 346-353.

CARGNELUTTI-FILHO A et al. 2007. Comparação de métodos de adaptabilidade e estabilidade relacionados à produtividade de grãos de cultivares de milho. Bragantia 66: 571-578.

CARVALHO CGP et al. 2002. Interação genótipo $x$ ambiente no desempenho produtivo da soja no Paraná. Pesquisa Agropecuária Brasileira 37: 989-1000.

CARVALHO IR et al. 2014. Desempenho agronômico de híbridos de milho em ambiente irrigado e sequeiro. Enciclopédia Biosfera 10: 1144-1153.

CHURATA BGM \& AYLA-OSUNA JT. 1996. Correlações genotípica, fenotípica e de ambiente e análise de trilha em caracteres avaliados no composto de milho (Zea mays) arquitetura. Ceres 43: 628-636.

CONAB. 2017. Companhia Nacional de Abastecimento. Acompanhamento da safra brasileira de grãos. v. 4, n. 5, 166p. Disponível em: <http://www.conab.gov.br/OlalaCMS/uploads/arquivos/17_02_16_11_51_51_boletim _graos_fevereiro 2017.pdf>. Acesso em: 21 fev. 2017.

COSTA EFN et al. 2010. Interação entre genótipos e ambientes em diferentes tipos de híbridos de milho. Pesquisa Agropecuária Brasileira 45: 1433-1440.

CRUZ CD. 2013. GENES - a software package for analysis in experimental statistics and quantitative genetics. Acta Scientiarum. Agronomy 35: 271-276.

DOURADO-NETO D et al. 2003. Efeito da população de plantas e do espaçamento sobre a produtividade de milho. Revista Brasileira de Milho e Sorgo 2: 63-77.

GUISCEM JM et al. 2002. Características morfológicas e fisiológicas do milho que influenciam a perda de água do grão. Revista Brasileira de Milho e Sorgo 1: 28-37.

KUMAR V et al. 2015. Correlation, path and genetic diversity analysis in maize (Zea mays L.). Environment \& Ecology 33: 971-975.

LEMOINE R et al. 2013. Source-to-sink transport of sugar and regulation by environmental factors. Frontiers in Plant Science 4: 1-21.

LOPES SJ et al. 2007. Relações de causa e efeito em espigas de milho relacionadas aos tipos de híbridos. Ciência Rural 37: 1536-1542.

NATARAJ V et al. 2014. Correlation and path analysis in certain inbred genotypes of maize (Zea Mays L.) at Varanasi. International Journal of Innovative Research and Development 3: 14-17.

NARDINO M et al. 2016. Diallel cross analysis in maize. International Journal of Current Research 8: 35686-35692.

NDHLELA T et al. 2014. Genotype x environment interaction of maize grain yield using AMMI biplots. Crop Science 54: $1992-1999$.

PARENTONI SN et al. 2013. Implications on the introduction of transgenics in Brazilian maize breeding programs. Crop Breeding and Applied Biotechnology 13: 9-22.

PENARIOL FG et al. 2003. Comportamento de cultivares de milho semeadas em diferentes espaçamentos entre linhas e densidades populacionais, na safrinha. Revista Brasileira de Milho e Sorgo 2: 52-60.

RAMALHO MAP et al. 2012. Aplicações da Genética Quantitativa no Melhoramento de Plantas Autógamas. 1.ed. Lavras. UFLA. 522p.

RIBEIRO JZ \& ALMEIDA MIM. 2011. Estratificação ambiental pela análise da interação genótipo $x$ ambiente em milho. 
Pesquisa Agropecuária Brasileira 46: 875-883.

SANGOI L et al. 2002. Bases morfológicas para maior tolerância dos híbridos modernos de milho a altas densidades de plantas. Bragantia 61: 101-110.

SANGOI L et al. 2010. Perfilhamento e prolificidade como características estabilizadoras do rendimento de grãos do milho, em diferentes densidades. Revista Brasileira de Milho e Sorgo 9: 254-265.

SANGOI L et al. 2011. Perfilhamento, área foliar e produtividade do milho sob diferentes arranjos espaciais. Pesquisa Agropecuária Brasileira 46: 609-616.

SANTOS RF \& CARLESSO R. 1998. Déficit hídrico e os processos morfológico e fisiológico das plantas. Revista Brasileira de Engenharia Agrícola e Ambiental 2: 287-294.

SERPA MS et al. 2012. Densidade de plantas em híbridos de milho semeados no final do inverno em ambientes irrigados e de sequeiro. Pesquisa Agropecuária Brasileira 47: 541-549.

SILVA PRF et al. 1999. Respostas de híbridos de milho irrigado à densidade de plantas em três épocas de semeadura. Pesquisa Agropecuária Brasileira 34: 585-592.

STORCK L et al. 2014. Análise conjunta de ensaios de cultivares de milho por classes de interação genótipo $x$ ambiente. Pesquisa Agropecuária Brasileira 49: 163-172.

VILELA RG et al. 2012. Desempenho agronômico de híbridos de milho, em função da aplicação foliar de fungicidas. Bioscience Journal 28: 25-33. 